\title{
Profile of unmet needs of family planning in an urban slum of Ganjam district, Odisha, India: a cross-sectional study
}

\author{
Smaranita Sabat, Dhaneswari Jena*, Durga Madhab Satapathy, \\ Sithun Patro, Radhamadhab Tripathy
}

Department of Community Medicine, MKCG Medical College, Odisha, India

Received: 01 January 2019

Accepted: 05 February 2019

\section{*Correspondence:}

Dr. Dhaneswari Jena,

E-mail: drdjena@rediffmail.com

Copyright: (C) the author(s), publisher and licensee Medip Academy. This is an open-access article distributed under the terms of the Creative Commons Attribution Non-Commercial License, which permits unrestricted non-commercial use, distribution, and reproduction in any medium, provided the original work is properly cited.

\begin{abstract}
Background: Unmet need for family planning refers to the percentage of fecund women of reproductive age either married or in union, women who either wish to postpone the next birth (spacers) or who wish to stop child bearing (limiters) but are not using a contraceptive method. This clearly indicates a gap between a woman's reproductive intention and current contraceptive behaviour. The objectives of the present study was to determine the prevalence of unmet need for family planning, to assess the association between socio-demographic characteristics and unmet need of family planning, to identify the reasons for unmet need.

Methods: It was a cross-sectional study conducted from June to August 2018 in Ankuli (UHTC). A total of 188 ever married women in the reproductive age group were selected by simple random sampling.

Results: Out of 188 women, $41(21.8 \%)$ had no need for contraception and needs for family planning of $78(41.5 \%)$ women had been met. The prevalence of unmet need for family planning was $36.7 \%$ consists of 24 (12.8\%) spacing need and $45(23.9 \%)$ limiting need. It was found that age, education of women, age at marriage, number of living children, contraceptive knowledge and inter-spousal communication were significantly associated with unmet need for family planning. The most common reason for not using any contraceptive method was fear of side effects $(40.6 \%)$.

Conclusions: The unmet need for family planning was high and in order to reduce the gap, the program should address the above reasons.
\end{abstract}

Keywords: Contraception, Family planning, Limiting, Spacing, Unmet need

\section{INTRODUCTION}

Family planning practice is the right of women, which empower her to achieve her reproductive goal. A woman's ability to space her pregnancies has a direct impact on her health and wellbeing as well as on the outcome of pregnancy. Family planning prevents unintended pregnancies, reduces infant mortality and maternal mortality, helps to prevent HIV/AIDS, reduces adolescent pregnancies and slows population growth. ${ }^{1}$ India was the first country in the world to have launched a National Programme for Family Planning in 1952. Over the decades, the programme has undergone transformation in terms of policy and actual programme implementation and currently being repositioned to not only achieve population stabilization goals but also promote reproductive health and reduce maternal, infant and child mortality and morbidity. ${ }^{2}$ Unmet need for family planning refers to the percentage of fecund women of reproductive age either married or in union, women who either wish to postpone the next birth (spacers) or who wish to stop child bearing (limiters) but are not using a contraceptive method. This clearly indicates a gap 
between a woman's reproductive intention and current contraceptive behaviour. ${ }^{3}$ Unmet needs show how well national family planning programs are achieving the key mission of meeting the population's felt need for family planning. It is a valuable indicator for tracking progress towards the target of achieving Universal access to reproductive health. NFHS-IV 2015-2016 (National Family Health Survey) in India revealed that the unmet need of family planning was $12.9 \%$ with $5.1 \%$ for spacing and $7.8 \%$ for limiting, while in the past decade it was $13.9 \% .^{4}$ According to NFHS-IV in Odisha the unmet need for family planning was $13.6 \%$ with $4.7 \%$ for spacing and $8.9 \%$ for limiting, while in past decade it was $16.0 \% .^{5}$ In Odisha the unmet need for family planning decreased during the past two decades total number of women with unmet need remaining the same due to population growth. The number of unintended pregnancies can be brought down by increasing favourable factors and reducing factor which reduces the utilization of family planning services. The objectives of the present study was to determine the prevalence of unmet need for family planning, to assess association between socio-demographic characteristics and unmet need for family planning, to identify the reasons for unmet needs.

\section{METHODS}

It was a community-based, cross-sectional study, carried out in an area covered under the Urban Health Training Center (UHTC), Ankuli of a MKCG medical college, Berhampur. The study was undertaken from June to August 2018. Sample size was calculated by the formula $4 \mathrm{pq} / 1^{2}$. As per National Family Health Survey (NFHS-4), the unmet need for family planning in Odisha is $13.6 \%$. Thus, $\mathrm{p}$ is 13.6. The allowable error was taken as $5 \%$. So, the sample size obtained was 188. Simple random sampling of the house hold was done to obtain the desired sample size. The study population consisted of ever married women in the reproductive age group (15-49 years). Women residing in the area for less than six months, women who were seriously ill and those who were non-cooperative were excluded from the study. Separated /divorced women, widows, women pregnant due to contraceptive failure were also excluded from the study. Clearance was obtained from the institutional ethics committee. A door-to-door survey was done for collection of the necessary information from the selected household. From family with two eligible women, one was selected randomly. After getting the targeted study population, the objectives of the study were explained, and informed consent was taken from each study participants. Data was collected using predesigned, pretested and semi structured questionnaire in local language.

\section{Inclusion criteria}

- All currently married women who were not using any method of contraception but did not desire any more children (limiters) or wanted to wait two or more years for the next child (spacers).

- Pregnant women with mistimed (spacers) or unwanted (limiters) pregnancy

- Amenorrhoeic women whose last delivery was mistimed (spacers) or unwanted (limiters).

\section{Statistical analysis}

The data were entered and were analyzed using the statistical software SPSS version 16. Rates and proportion were calculated. Chi-square test was used for finding the association. A P-value of less than 0.05 was considered to be statistically significant.

\section{RESULTS}

The mean age of the study population was $29.19 \pm 6$. 85 years. Out of 188 women, $48.9 \%$ were aged between 19 -30 years and $8 \%$ were in the age group of $<18$ years.

Table 1: Socio-demographic profile of the respondents $(n=188)$.

\begin{tabular}{|l|l|l|}
\hline Variables & Frequency & $\%$ \\
\hline Age of women & 15 & 8 \\
\hline <18 years & 92 & 48.9 \\
\hline $\begin{array}{l}\text { 19-30 years } \\
\text { 31-40 years }\end{array}$ & 62 & 33 \\
\hline >41 years & 19 & 10.1 \\
\hline Wife's education & 32 & 17 \\
\hline Illiterate & 88 & 46.8 \\
\hline <10th & 52 & 27.7 \\
\hline 10-12th & 16 & 8.5 \\
\hline Graduate and above & & \\
\hline Husband's occupation & 84 & 44.7 \\
\hline Skilled & 88 & 46.8 \\
\hline Unskilled & 16 & 8.5 \\
\hline Professional & & \\
\hline Age of marriage & 46 & 24.5 \\
\hline$<18$ years & 77 & 41 \\
\hline 18-25 years & 59 & 31.4 \\
\hline 26-29 years & 6 & 3.2 \\
\hline >30 years & & \\
\hline Socioeconomic status & 26 & 13.8 \\
\hline Upper and upper middle & 27 & 14.4 \\
\hline Lower middle & 103 & 54.8 \\
\hline Upper lower & 32 & 17.0 \\
\hline Lower & 103 & 54.8 \\
\hline Type of family & 85 & 45.2 \\
\hline Nuclear & 57 & 36.3 \\
\hline Joint & 69 & \\
\hline No. of living children & & \\
\hline 0-1 & & \\
\hline 2 & & \\
\hline >3 & & \\
\hline & & \\
\hline
\end{tabular}

$17 \%$ women were illiterate. Early marriage i.e. marriage before 18 years of age was found in $24.5 \%$ women. Most 
of the women belonged to the upper lower socioeconomic class i.e. $54.8 \%$ according to modified Kuppuswamy's socioeconomic scale. $54.8 \%$ women lived in nuclear family. $36.7 \%$ women had more than 3 children (Table $1)$.

Out of 188 women $41(21.8 \%)$ had no need for contraception as they were planning for a child in near future. Family planning needs of 78 (41.5\%) women had been met as they were using one or other family planning methods. The prevalence of unmet need was $36.7 \%$ with $24(12.8 \%)$ for spacing and $45(23.9 \%)$ for limiting (Figure 1).

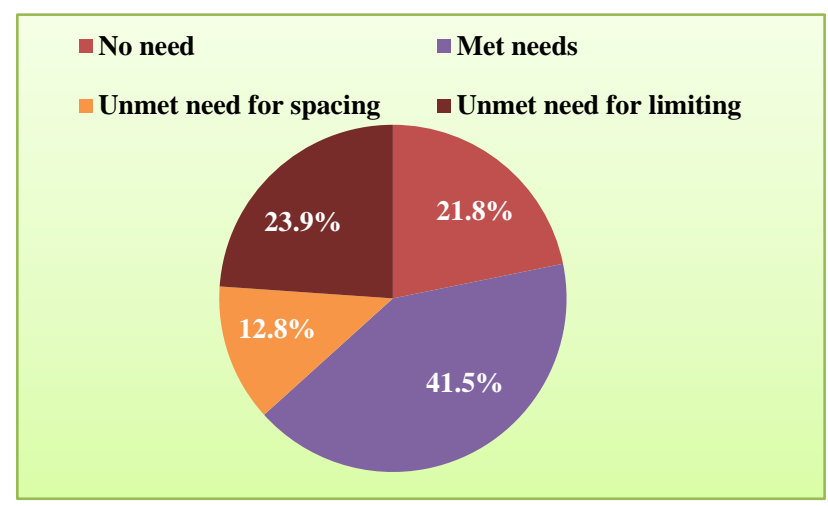

Figure 1: Distribution according to their need for contraception $(n=188)$.

It was found that age, education of women, age of marriage, number of living children, contraceptive knowledge and discussion about contraceptive practice with husband were significantly associated with unmet need for family planning. The prevalence of unmet need in women aged <18yrs was higher i.e. $73.3 \%$ and it significantly decreased as the age of women increased. Similar trend was seen in case of education of women i.e. illiterate women had higher unmet need $(62.5 \%)$. The unmet need was significantly higher among women who were married before the legal age of marriage $(<18$ years) as compared to those who were married after 18 years of age. The unmet need significantly decreased as the no. of living children increased.

The prevalence is $58.4 \%$ in women having 0 and 1 living children. Fewer unmet need $(14.6 \%)$ was found in those having better contraceptive knowledge. Those women who discussed about contraceptive practice with their husband have lower unmet need i.e. $17.6 \%$ as compared to those who had no discussion about contraceptive practice with their husband (Table 2).

Table 3 describes that fear of side effect (40.6\%) was found to be major reason followed by low perceived risk of pregnancy (29\%) for unmet need of family planning. But $17 \%$ women stated opposition from family or partner as a reason for unmet need of family planning. Lack of knowledge and medical reasons were the reasons for unmet need of family planning in $8.7 \%$ and $4.3 \%$ of women respectively.

Table 2: Association between unmet need for family planning and socio-demographic characteristics of the study participants $(n=188)$.

\begin{tabular}{|c|c|c|c|c|c|}
\hline \multirow{3}{*}{ Variables } & \multicolumn{4}{|c|}{$\begin{array}{l}\text { Unmet needs of family } \\
\text { planning }\end{array}$} & \multirow{3}{*}{$P$ value } \\
\hline & \multicolumn{2}{|c|}{ Absent } & \multicolumn{2}{|c|}{ Present } & \\
\hline & No. & $(\%)$ & No. & $(\%)$ & \\
\hline \multicolumn{5}{|l|}{ Age of women } & \multirow{5}{*}{$0.011 *$} \\
\hline$<18$ year & 4 & 26.7 & 11 & 73.3 & \\
\hline 19-30 year & 58 & 63.0 & 34 & 37.0 & \\
\hline $31-40$ year & 42 & 67.7 & 20 & 32.0 & \\
\hline$>41$ year & 15 & 78.9 & 4 & 21.1 & \\
\hline \multicolumn{5}{|l|}{$\begin{array}{l}\text { Education of } \\
\text { women }\end{array}$} & \multirow{5}{*}{$0.010 *$} \\
\hline Illiterate & 12 & 37.5 & 20 & 62.5 & \\
\hline$<10$ th & 59 & 67.0 & 29 & 33.0 & \\
\hline $10-12$ th & 36 & 69.2 & 16 & 30.8 & \\
\hline $\begin{array}{l}\text { Graduate and } \\
\text { above }\end{array}$ & 12 & 75.0 & 4 & 25.0 & \\
\hline \multicolumn{5}{|l|}{$\begin{array}{l}\text { Husband's } \\
\text { occupation }\end{array}$} & \multirow{4}{*}{0.241} \\
\hline Skilled & 48 & 57.1 & 36 & 42.9 & \\
\hline Unskilled & 59 & 67.0 & 29 & 33.0 & \\
\hline Professional & 12 & 75.0 & 4 & 25.0 & \\
\hline \multicolumn{5}{|l|}{ Age of marriage } & \multirow{5}{*}{$0.001 *$} \\
\hline$<18$ years & 18 & 39.1 & 28 & 60.9 & \\
\hline $18-25$ years & 53 & 68.8 & 24 & 31.2 & \\
\hline $26-29$ years & 44 & 74.6 & 15 & 25.4 & \\
\hline$>30$ years & 4 & 66.7 & 2 & 33.3 & \\
\hline \multicolumn{5}{|l|}{$\begin{array}{l}\text { Socioeconomic } \\
\text { status }\end{array}$} & \multirow{5}{*}{0.962} \\
\hline $\begin{array}{l}\text { Upper and } \\
\text { upper middle }\end{array}$ & 17 & 65.4 & 9 & 34.6 & \\
\hline Lower middle & 17 & 63.0 & 10 & 37.0 & \\
\hline Upper lower & 66 & 64.1 & 37 & 35.9 & \\
\hline Lower & 19 & 59.4 & 13 & 40.6 & \\
\hline \multicolumn{5}{|l|}{ Type of family } & \multirow{3}{*}{0.504} \\
\hline Nuclear & 63 & 61.2 & 40 & 38.8 & \\
\hline Joint & 56 & 65.9 & 29 & 34.1 & \\
\hline \multicolumn{5}{|l|}{$\begin{array}{l}\text { No. of living } \\
\text { children }\end{array}$} & \multirow{4}{*}{$0.001 *$} \\
\hline $0-1$ & 25 & 43.9 & 32 & 56.1 & \\
\hline 2 & 43 & 69.4 & 19 & 30.6 & \\
\hline$\geq 3$ & 51 & 73.9 & 18 & 26.1 & \\
\hline \multicolumn{5}{|l|}{$\begin{array}{l}\text { Contraceptive } \\
\text { knowledge }\end{array}$} & \multirow{3}{*}{$0.000 *$} \\
\hline Poor & 31 & 36.5 & 54 & 63.5 & \\
\hline Good & 88 & 85.4 & 15 & $\begin{array}{l}14 . \\
6\end{array}$ & \\
\hline \multicolumn{5}{|l|}{$\begin{array}{l}\text { Discussion with } \\
\text { husband }\end{array}$} & \multirow{3}{*}{$0.001 *$} \\
\hline No & 77 & 56.2 & 60 & 43.8 & \\
\hline Yes & 42 & 82.4 & 9 & 17.6 & \\
\hline
\end{tabular}


Table 3: Reasons for unmet need of family planning $(n=69)$.

\begin{tabular}{|l|l|}
\hline Reasons & No. $(\%)$ \\
\hline Fear of side effect & $28(40.6)$ \\
\hline Lack of knowledge & $6(8.7)$ \\
\hline Opposition from family or partner & $12(17.4)$ \\
\hline Little perceived risk of pregnancy & $20(29)$ \\
\hline Medical reasons & $3(4.3)$ \\
\hline
\end{tabular}

\section{DISCUSSION}

In the present study $36.7 \%$ women had an unmet need for family planning with $12.8 \%$ for spacing and $23.9 \%$ for limiting. The unmet need observed in this study is higher than Annual Health Survey 2012-13 report, where the unmet need for family planning in Ganjam district of Odisha is $22.9 \%$ with $11.3 \%$ for spacing and $11.6 \%$ for limiting. ${ }^{6}$ Higher unmet need was also seen in studies by Pal et al in Lucknow, Begum et al in Mumbai and Valekar et al in Pune where it was $53.1 \%, 40.6 \%$ and $42 \%$ respectively. ${ }^{7-9}$ However in studies by Raveendran et al in Karnataka, Jesh et al in Kerala and Nazir et al in Haryana unmet needs for family planning were $16.7 \%$, $21.2 \%$ and $7.5 \%$ respectively. ${ }^{10-12}$ Thus authors see that there is a considerable variation in unmet need due to social and cultural differences.

The unmet need was highest among women $<18$ years of age i.e. $73.3 \%$ and it decreased with increase in age. Similar results were seen in studies conducted by Pal et al in Lucknow and Begum et al in Mumbai, where the unmet needs decreased with increase in age. ${ }^{7,8}$ However in studies conducted by Patel et al and Vasudevan et al it was higher in women aged 25-34 years. ${ }^{13,14}$ In another study by Singh et al unmet need was highest in 35-44 years age group. ${ }^{15}$ Nazish et al concluded that women below 35 years of age had higher unmet need for family planning in comparison to those above 35 years. ${ }^{16}$ This can be attributed to the fact that the young couples do not have sufficient knowledge of various contraceptive methods available.

In present study it was found that unmet needs for family planning significantly decreased with improvement of educational status. Similar results were reported in studies by Vohra et al and Relwani et al where the unmet need decreased with improvement of educational level. ${ }^{17,18}$ However in a study by Prasad et al in Kanchipuram district of Tamil Nadu, women who were educated above high school had higher unmet needs $(36.7 \%)$ than women who had an education level of middle school and below (27\%). ${ }^{19}$ Observation in present study contradicts that of the study of Valekar et al and Rasheed et al who reported no significant association between unmet needs for family planning and educational level of women. ${ }^{9,16}$ It may be concluded that educating women and empowering them will greatly reduce the burden of unmet need for family planning.
Of the women who were married before the legal age of marriage, $60.9 \%$ had unmet need for family planning. It was lower for those who had married after 18 years of age and this association was found to be significant. Our finding was supported by Bhattathiry et al where unmet needs decreased as the age at marriage rose. ${ }^{20}$ However there was no significant association between age of marriage and unmet need in a study conducted by Prasad et al. ${ }^{19}$ In present study occupation of husband, socioeconomic status of women and type of family were not found to be significantly associated with unmet needs.

It was reported that the unmet need for family planning was lowest among those who had more than three living children $(26.1 \%)$ as compared to those with two living children $(30.6 \%)$ and one or no living child $(56.1 \%)$. There was a significant association between number of living children and unmet needs. This finding in present study was in accordance with many other studies. . $^{70,17-20}$ It may be due to the fact that those women who already had three or more than three living children would like to restrict childbearing and adopt any contraceptive methods while those with one or no child might not have achieved their desired family size thus, not so receptive to the use of family planning measures.

In the present study unmet need was significantly higher in women with poor contraceptive knowledge $(63.5 \%)$ as compared to women with good contraceptive knowledge $(14.6 \%)$. It was also found that women who had discussion with their husbands on family planning were less likely to have unmet needs for family planning (17.6\%) than women whose husbands were not involved $(43.8 \%)$. This difference was statistically significant. This has been consistently reported by most of the other studies done in India. ${ }^{7,12-16,20}$ Thus it can be concluded that inter-spousal communication is a significant determinant for reducing unmet needs for family planning.

Present study found that the commonest reason for nonusage of contraceptive methods were fear of side effect $(40.6 \%)$ and lower perceived risk of pregnancy (29\%).Vasudevan et al in their study found that client related factors like lack of knowledge, shyness and fertility problems $(46 \%)$ as the common reasons for nonusage of contraception by those with unmet need. ${ }^{14}$ Nazir et al reported that family inhibition, cost of contraception, concern about infertility and unhappiness with healthcare services were significantly associated with unmet need. ${ }^{12}$ Singh et al reported that the commonest reason for nonusage of contraceptive methods was fear of side-effects (37.5\%) followed by in-laws disapproval (21.9\%) which is similar to present study. ${ }^{15}$

\section{CONCLUSION}

In the present study, unmet need for family planning was higher than the national and state statistics. Younger age, 
lower level of education, early marriage, poor contraceptive knowledge and no inter-spousal communication regarding family planning practice were identified as the significantly contributing factors for higher unmet needs. The most common reason for not using any contraceptive method among women with unmet need was fear of side effects followed by lower perceived risk of pregnancy.

\section{Recommendations}

The health care provider at grass root level should motivate the couple and provide appropriate information regarding various contraceptive methods. They should also highlight the benefits of family planning at VHND sessions and during home visits. Simultaneously they should counsel properly about the fear of side effect which is the major obstacle in acceptance of family planning measures. Efforts should be made to improve literacy of women and to empower them; this will lead to good contraceptive knowledge which in turn will decrease the burden of unmet needs. Attention should be paid for ensuring universal adherence to the legal age for marriage. The family planning programme should focus on men as well, as they often play an important and dominant role in the decision pertaining to the family size and the use/non-use of family planning methods. As it is seen more unmet need among nuclear family, spousal communication for making decision regarding family planning are important determinant and should be encouraged as this will bridge the gap between met and unmet need. More emphasis should be given to provide contraceptive information through the mass media.

\section{Funding: No funding sources}

Conflict of interest: None declared

Ethical approval: The study was approved by the Institutional Ethics Committee

\section{REFERENCES}

1. WHO Family planning/Contraception. WHO [Internet]. 2017 [cited 2017 Oct 12]; Available from: http://www.who.int/mediacentre/factsheets/fs351/en/

2. Family Planning : Background - Governnment of India. Available from: http://nhm.gov.in/nrhmcomponents/rmnch-a/family-

planning/background.html

3. WHO. WHO | Unmet need for family planning [Internet]. Who. World Health Organization; 2016 Available from: http://www.who.int/reproductivehealth/topics/family _planning/unmet_need_fp/en/ Welfare) I (Health \& F.

4. National Family Health Survey. India Fact Sheet. 2015. Available from: http://rchiips.org/NFHS/pdf/NFHS4/India.pdf

5. Pradesh H. Ministry of Health and Family Welfare State Fact Sheet. Available from:
http://rchiips.org/NFHS/pdf/NFHS4/OR_FactSheet.p df

6. Vital Statistics Division, Office of the Registrar General \& Census Commissioner I, New Delhi. Annual health survey 2012-13 fact sheet, Vital Statistics Division Office of the Registrar General \& Census Commissioner, India New Delhi. 2012; Available from: www.censusindia.gov.in

7. Pal A, Mohan U, Idris MZ, Masood J. Factors affecting unmet need for family planning in married women of reproductive age group in urban slums of Lucknow. Indian J Community Heal. 2014;26(1):449.

8. Begum S, Nair S, Donta B, Prakasam C. Prevalence of unmet need for contraception in urban slum communities, Mumbai. Int J Reprod Contraception, Obstet Gynecol. 2014;3(3):627-30.

9. Mane A, Chawla P, Pandve H, Valekar S. Assessment of Unmet Needs of Family Planning and Reasons for Non-Use of Contraceptive Methods among Women in Reproductive Age in Rural Community. J Community Med Health Educ. 2017;7(4):2-5.

10. Raveendran R, Vijayakumar B. Unmet need for family planning in South India. Int $\mathbf{J}$ Biomed $\mathrm{Adv}$ Res. 2017;8(3):82-6.

11. Mm J, Nm S, Haveri SP, Nath AS. Unmet needs for family planning in a municipal area in North Kerala, India. Int J Reprod Contraception, Obstet Gynecol. 2016;5(7):2322-7.

12. Nazir S, Mittal A, K Anand B, Goel R, Singh J, Arshad R. Determinants of Unmet Need for Family Planning In a Developing Country: An Observational Cross Sectional Study. Natl J Community Med. 2015;6(1):86-91.

13. Patel BH, Gandha KM, Koringa HT, Mehta JP, Parmar D V, Sudha B Yadav. A Community Based Cross-Sectional Study to Assess the Unmet Need of Family Planning in Urban Slums and It's Determinants in Western Part of India. Natl J Med Res. 2014;4(1):7-9.

14. Vasudevan K, Soundarya C. Assessment of unmet need for contraception in an urban area of Pondicherry. Natl J Res Community Med. 2016;5(4):223-8.

15. Singh S, Kalhan M, Malik JS, Jangra A, Sharma N, Singh S. Assessment of unmet need for family planning and its determinants in a rural block of Haryana. Int $\mathbf{J}$ Community Med Public Heal. 2018;5(5):1968-73.

16. Rasheed N, Khan Z, Khalique N, Siddiqui AR, Hakim S. Unmet need of contraception among married women of reproductive age group in Uttar Pradesh, India. Int $\mathbf{J}$ Med Heal Sci Res. 2016;5(1):14-9.

17. Vohra R, Vohra A, Rathore M, Sharma S, Sharma B, Sharma M. Determinants of the unmet need for family planning among women of Jaipur, Rajasthan. Int J Adv Med Res. 2014;1(1):20. 
18. Relwani NR, Saoji A V, Kulkarni M, Kasturwar N, Zade R, Wadke R. Revealing unmet need for contraception among married women in an urban slum of Nagpur. J Med Sci Pub Health. 2015;4(8):26.

19. Vishnu Prasad R, Venkatachalam J, Singh Z. Unmet Needs of Family Planning Among Women: A CrossSectional Study in a Rural Area of Kanchipuram District, Tamil Nadu, South India. J Obstet Gynecol India. 2016;66(1):1-6.
20. Bhattathiry MM, Ethirajan N. Unmet need for family planning among married women of reproductive age group in urban Tamil Nadu. J Fam Community Med. 2014;21(1):53.

Cite this article as: Sabat S, Jena D, Satapathy DM, Patro S, Tripathy R. Profile of unmet needs of family planning in an urban slum of Ganjam district, Odisha, India: a cross-sectional study. Int $\mathrm{J}$ Reprod Contracept Obstet Gynecol 2019;8:961-6. 